\title{
Surgical ciliated cyst after a mandibular surgery: a particular case report and review of the literature
}

\author{
Irene Lafuente-Ibáñez de Mendoza ${ }^{1 *} \mathbb{D}$, Marta Fernández-Reyes ${ }^{2}$, Antonio Fernández-Arenas ${ }^{2}$ and \\ José Manuel Aguirre-Urizar ${ }^{1}$
}

\begin{abstract}
Background: Surgical ciliated cyst is a rare clinicopathological lesion that appears in patients who undergo maxillofacial surgery. In this report we present a particular mandibular case and we discuss the etiopathogenesis and clinicopathological features of this pathology after reviewing the current literature, as well as the origin of its respiratory epithelial profile.
\end{abstract}

Case presentation: The patient is a 67-year-old male with an irregular radiolucency in a previously tooth extracted area of the mandible. The histopathological study revealed a cystic lesion with a connective wall with chronic inflammation, partially lined by a ciliated pseudostratified epithelium. PAS and CK19 stains showed the respiratory characteristics of this epithelium and confirmed the final diagnosis of mandibular surgical ciliated cyst.

Conclusions: Surgical ciliated cyst is an uncommon entity associated with maxillofacial surgical procedures with bone and nasal cartilage grafts. In our case, treatment with growth factors present in platelet-rich plasma could explain the respiratory changes observed in the cystic epithelial lining."

Keywords: Surgical ciliated cyst, Mandible, Growth-factors, Pathogenesis, Review

\section{Background}

The surgical ciliated cyst is an uncommon and benign entity described by Kubo in 1927 that occurs in the maxillary bones that have previously been surgically treated (orthognathic surgery, plastic surgery, etc.) [1-3]. This pathology is slightly more frequent in men and usually appears as an asymptomatic radiolucency, with or without swelling [4]. The treatment of the surgical ciliated cyst is simple enucleation, and its recurrence rate is low $(20 \%)[5,6]$.

It is believed that the origin of the maxillary cases could derive from rests of sinus mucosa that remain trapped in

\footnotetext{
*Correspondence: Ilafuente94@gmail.com

${ }^{1}$ Department of Stomatology II, Faculty of Medicine and Nursery,

University of the Basque Country, Barrio Sarriena s/n, 48940 Leioa, Spain

Full list of author information is available at the end of the article
}

the bone and maintain their proliferative potential [7]. On the contrary, mandibular cases have been more difficult and controversial to explain since its initial description in 1994 [8].

In this report, we present the first case of a surgical ciliated cyst of the mandible unrelated to a major maxillofacial surgery and we discuss its main etiopathogenic and clinicopathological aspects, as well the etiology of its respiratory epithelial profile.

\section{Case presentation}

A 67-year-old man under treatment with antihypertensives and anticoagulants due to cardiac arrhythmia was referred to a dental private practice complaining of a mandibular pain in the fourth quadrant. He had 
experienced multiple abscesses associated with a fixed dental prosthesis since 2018.

Radiographic examination showed the inclusion of 4.5 and a complex endo-periodontal radiolucent lesion on 4.6, with double root fracture and hypercementosis. CT scan revealed an extensive circumferential alveolar bone loss (Fig. 1A). Under local anesthesia, tooth 4.5 and 4.6 were removed and the alveolar lesion was curetted. The bone defect was filled with platelet-rich plasma and a collagen membrane (Creos Xenoprotec $\left.{ }^{\circledR}\right)$, fixed with titanium micro-screws $\left(\right.$ Bioner $\left.^{\circledR}\right)$. On a follow-up examination, an irregular radiolucency was observed in the surgically treated area two years before (Fig. 1B). Under local anesthesia, a cystic lesion was excised and submitted for histopathologic analysis with the presumptive diagnosis of residual cyst (Fig. 2).

The tissue specimen consisted of a dark brown and irregularly-shaped fragment of soft tissue, measuring $1.2 \times 1 \times 1 \mathrm{~cm}$ and brownish cut surface. Microscopic

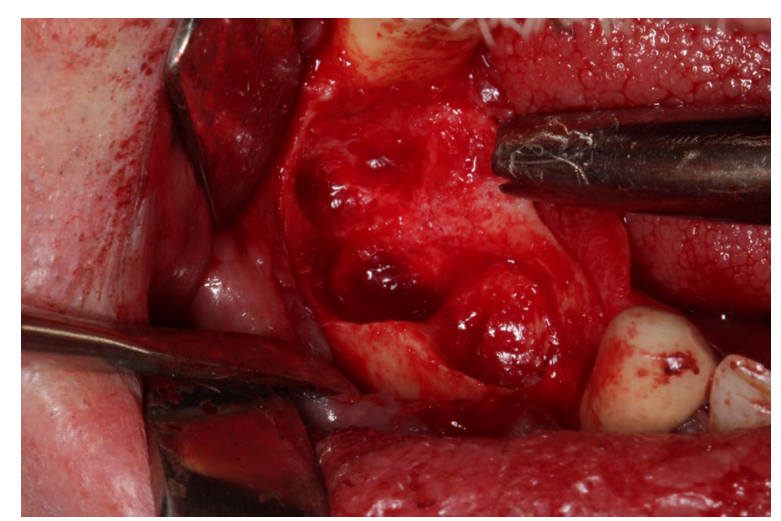

Fig. 2 Surgical aspect. Absence of alveolar osseous regeneration and presence of soft cystic lesion

examination showed a thick fibrocollagenous connective tissue wall with different densities and a chronic inflammatory infiltrate (Fig. 3A). The epithelial lining

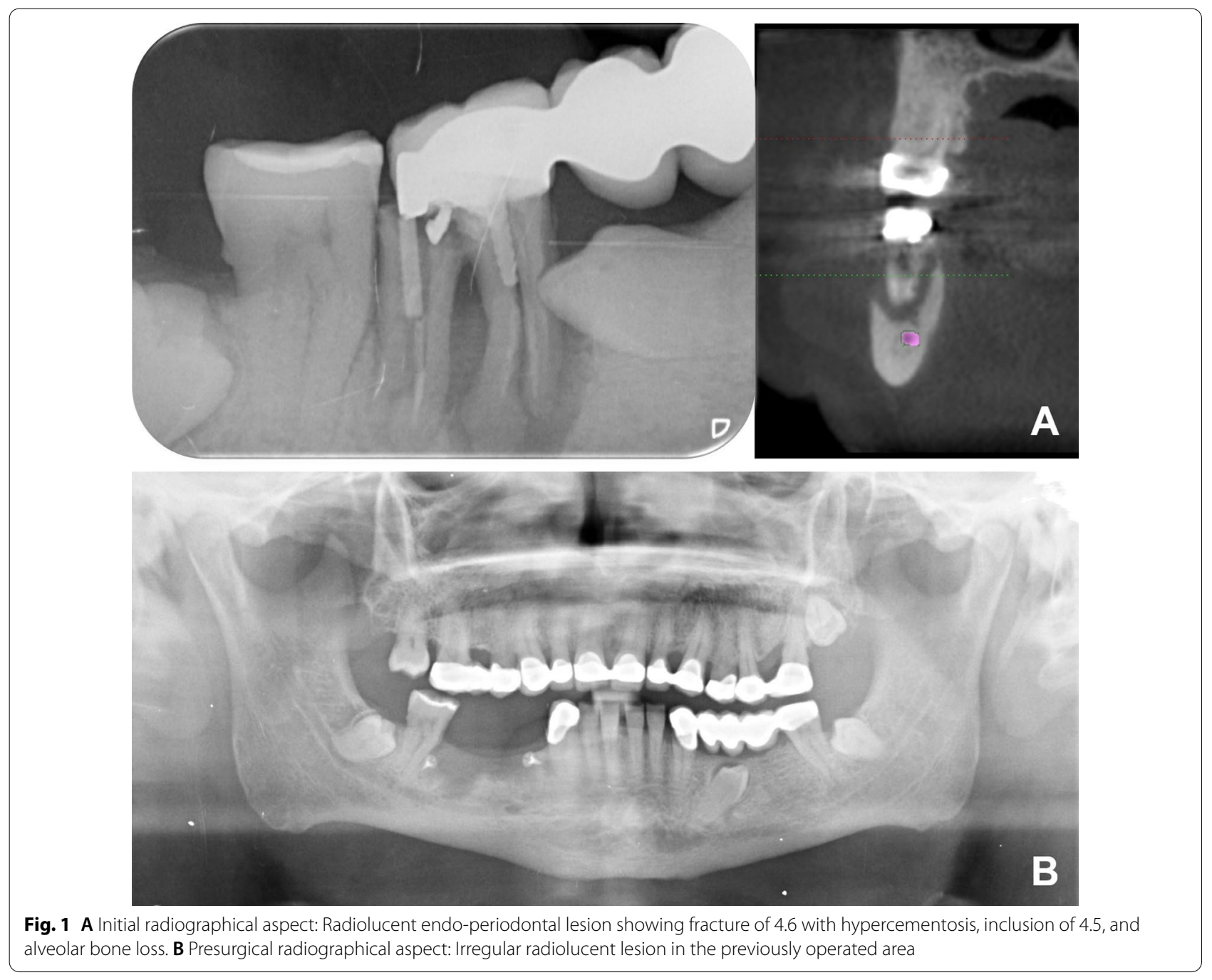




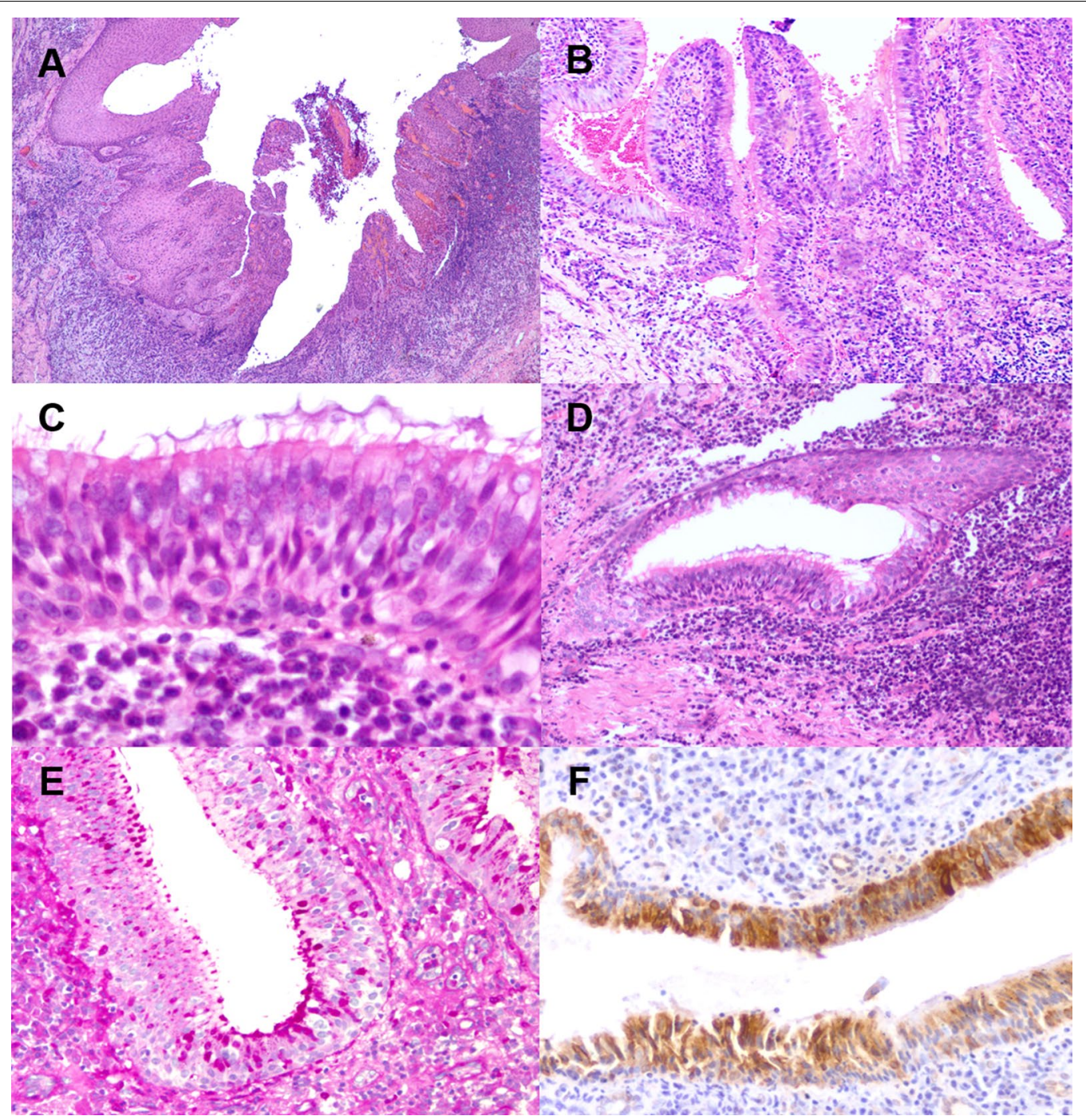

Fig. 3 Histopathological features. A Connective tissue wall with chronic inflammation, lined by a hyperplastic non-keratinized stratified epithelium with inflammatory exocytosis (10x, H\&E); $\mathbf{B}$ pseudostratified epithelial lining with papillary arrangement (20x, H\&E); $\mathbf{C}$ detail of the pseudostratified ciliated epithelium (40x, H\&E); D parietal nest with foci of epithelial transition (25x, H\&E); E) PAS (+) cells in the metaplastic epithelium (30x); $\mathbf{F}$ positive immunohistochemical expression of CK19 in the epithelial lining (30x)

consisted of a non-keratinised and hyperplastic stratified epithelium with inflammatory exocytosis, that presented large areas of ciliated pseudostratified epithelium with papillary foci (Fig. 3B, C). Epithelial nests were observed in the parietal connective tissue, showing the transition between non-keratinised stratified epithelium and ciliated pseudostratified epithelium (Fig. 3D). Positivity for CK19 (RCK108, ThermoFisher, Thermo Fisher Scientific, Waltham, MA $\left.{ }^{\circledR}\right)$ and PAS $(+)$ mucous cells confirmed the respiratory profile of the epithelium (Fig. 3E, F).

Based on these data, the final diagnosis of the lesion was surgical ciliated cyst of the mandible. At a one-year of follow-up there was no evidence of recurrence or complications.

\section{Discussion and conclusions}

The prevalence of the surgical ciliated cyst is variable (3-20\% of patients with history of maxillofacial surgery), and it is more frequently located in the upper maxilla [9, 10]. The first mandibular case was reported in a woman who underwent chin augmentation with a subperiosteal bone and nasal cartilage graft [8].

After performing a literature review on the surgical ciliated cyst of the mandible, we found 12 clinical cases [2, 8-15] (Table 1). The age of patients ranged from 
Table 1 Main clinicopathological features of the mandibular surgical ciliated cyst

\begin{tabular}{|c|c|c|c|c|c|}
\hline References & Patient (age/sex) & Location (Mandible) & Symptoms & Surgery & $\begin{array}{l}\text { Evolution } \\
\text { (years) }\end{array}$ \\
\hline Nastri and Hookey [8] & $33 / F$ & Anterior & Swelling, pain & Rhinoplasty, chin augmentation & 15 \\
\hline Anastassov and Lee [20] & $53 / \mathrm{M}$ & Anterior & Swelling & Rhinoplasty, chin augmentation & 39 \\
\hline Kelly et al. [21] & $56 / F$ & Anterior & Swelling, pain & Rhinoplasty, genioplasty & 40 \\
\hline Imholte and Schwartz [22] & $59 / \mathrm{M}$ & Anterior & Swelling & Rhinoplasty, chin augmentation & 40 \\
\hline Koutlas [1 1] & $34 / F$ & - & Swelling & Orthognathic & 21 \\
\hline Bourgeois et al. [2] & $24 / F$ & - & Radiolucency & Orthognathic, genioplasty & 4 \\
\hline Lazar et al. [19] & $24 / \mathrm{M}$ & - & Swelling, fistula & Rhinoplasty, mentoplasty & 5 \\
\hline Ragsdale et al. [12] & $30 / \mathrm{M}$ & Anterior & Swelling, fistula & Orthognathic & 16 \\
\hline Cai et al. [14] & $23 / M$ & - & Swelling & Orthognathic, genioplasty & 2 \\
\hline Seifi et al. [9] & $31 / F$ & Anterior & Swelling & Orthognathic, genioplasty & 2 \\
\hline \multirow[t]{2}{*}{ Syyed et al. [15] } & $38 / \mathrm{M}$ & Anterior & Radiolucency & Orthognathic, genioplasty & 18 \\
\hline & $25 / F$ & Anterior & Swelling & Orthognathic, genioplasty & 10 \\
\hline Current case & $50 / \mathrm{M}$ & Posterior & Radiolucency & Platelet-rich plasma, collagen membrane & $>2$ \\
\hline
\end{tabular}

33 to 59 years (mean: $36.9 \pm 13$ years), and males and females were equally affected. The diagnosis of these lesions occurred from 2 to 40 years after the surgery, mainly as a swelling on the chin area, or an asymptomatic radiographic finding. In most cases the surgical history was of rhinoplasty, orthognathic surgery or genioplasty (Table 1). Our patient is the first associated to a bone augmentation surgery. The treatment of choice in all reports was complete excision and curettage, and no recurrences have been reported.

The presence of respiratory epithelium in the upper maxillary odontogenic cysts (radicular cyst, dentigerous cyst, odontogenic keratocyst) is uncommon $[16,17]$. Regarding the surgical ciliated cyst, the use of bone grafts from the maxilla and/or nasal cartilage could explain the presence of the ciliated pseudostratified epithelium [8, $12,18,19]$. In the cases without grafting, the transplantation of respiratory epithelial rests during the bimaxillary surgical procedure is the etiopathogenic hypothesis more frequently considered [2, 14-16, 20, 21]. Nevertheless, the existence of this particular epithelium is more difficult to explain in cases without a major maxillofacial surgery, as in our patient.

We believe that the platelet-rich plasma (PRP) used for the bone augmentation and the history of a previous chronic severe inflammatory lesion could be the key pathogenic elements of our atypical case. PRP is a concentrated solution containing multiple secreted proteins, such as platelet-derived growth factor (PDGF), transforming growth factor (TGF)- $\beta$, endothelial growth factor (VEGF), epidermal growth factor (EGF), fibroblast growth factor (FGF) and insulin-like growth factor (IGF) $[23,24]$. It has been reported that some of these mitogenic factors promote proliferation, differentiation and maturation of odontogenic epithelial cells and trigger the formation of a cystic lesion, as well as areas of respiratory metaplasia [25]. On the other hand, we know that certain inflammatory mediators are actively involved in the development of maxillary cystic lesions (interleukins 1,13) [26]. These proteins lead to the overexpression of cell growth factors, and participate in the proliferation and ciliated metaplasia of the epithelium [27].

In this special case we think that there are 2 histogenetic possibilities that could explain the appearance of the cyst. The first is that the combination of factors from the PRP and the chronic inflammatory response induced the development of a de novo cyst over the mesenchymal alveolus site after the initial surgery, with extensive areas of respiratory epithelial metaplasia. The second is that remnants of the previous endo-periodontal inflammatory odontogenic lesion remained in the alveolus site after the initial surgery, over which the PRP factors and inflammatory proteins acted, inducing their proliferation, growth and respiratory epithelial metaplasia.

In summary, the surgical ciliated cyst of the mandible is an uncommon clinicopathological entity that occurs in patients with history of a maxillofacial surgery, mostly associated with maxillary bone-cartilage grafts. Our case is the first to develop in a patient treated with plateletrich plasma. Thus, it is very important to make a good clinical history and follow-up of all patients treated surgically in the jaw bones.

\section{Abbreviations}

CK: Cytokeratin; CT: Computed tomography; EGF: Epidermal growth factor; FGF: Fibroblast growth factor; IGF: Insulin-like growth factor; PAS: Periodic acid-Schiff; PDGF: Platelet-derived growth factor; PRP: Platelet-rich plasma; TGF- $\beta$ : Transforming growth factor beta; VEGF: Endothelial growth factor. 


\section{Acknowledgements \\ Not applicable.}

\section{Authors' contributions}

ILIM made substantial contributions to the conception and design of the work, the analysis and interpretation of data, and drafted the work. MMR made substantial contributions to the acquisition of data, and substantively revised the work. AFA made substantial contributions to the acquisition of data, and substantively revised the work. JMAU made substantial contributions to the conception and design of the work, interpretation of data, and substantively revised the work. All authors read and approved the final manuscript.

\section{Funding}

Authors have nothing to declare.

\section{Availability of data and materials}

All data generated or analysed during this study are included in this published article [and its supplementary information files]

\section{Declarations}

\section{Ethics approval and consent to participate}

The patient firmed an informed consent and data were dissociated for the analysis.

\section{Consent for publication}

A written consent to publish this information was obtained from study participants.

\section{Competing interests}

The authors declare that they have no competing interests.

\section{Author details}

${ }^{1}$ Department of Stomatology II, Faculty of Medicine and Nursery, University of the Basque Country, Barrio Sarriena s/n, 48940 Leioa, Spain. ${ }^{2}$ Arenas Clinic Private Service, Corredera de San Marcos, 37, 23700 Linares, Spain.

Received: 23 July 2021 Accepted: 26 November 2021

Published online: 09 December 2021

\section{References}

1. Kubo I. A buccal cyst occurred after a radical operation of the maxillary sinus. Z f Otol Tokyo. 1927;33:896-7.

2. Bourgeois SL, Nelson BL. Surgical ciliated cyst of the mandible secondary to simultaneous Le Fort I osteotomy and genioplasty: report of case and review of the literature. Oral Surg Oral Med Oral Pathol Oral Radiol End. 2005;100(1):36-9.

3. Golaszewski J, Muñoz R, Barazarte D, Perez L. Surgical ciliated cyst after maxillary orthognathic surgery: a literature review and case report. Oral Maxillofac Surg. 2019;23(3):281-4.

4. Amin M, Witherow $H$, Lee R, Blenkinsopp P. Surgical ciliated cyst after maxillary orthognathic surgery: report of a case. J Oral Maxillofac Surg. 2013;61(1):138-41.

5. Yoshikawa Y, Nakajima T, Kaneshiro S, Sakaguchi M. Effective treatment of the postoperative maxillary cyst by marsupialization. J Oral Maxillofac Surg. 1982;40(8):487-91.

6. Cano J, Campo J, Alobera MA, Baca R. Surgical ciliated cyst of the maxilla. Clinical case. Med Oral Patol Oral Cir Bucal. 2009;4(7):e361-4.

7. Yamamoto S, Maeda K, Kouchi I, Hirai Y, Taniike N, Imai Y, et al. Surgical ciliated cyst following maxillary sinus floor augmentation: a case report. J Oral Implantol. 2017:43(5):360-4.

8. Nastri AL, Hookey SR. Respiratory epithelium in a mandibular cyst after grafting of autogenous bone. Int J Oral Maxillofac Surg. 1994;23(69):372-3.

9. Seifi S, Sohanian S, Khakbaz O, Abesi F, Aliakbarpour F, Rayani A. Ectopic ciliated cyst in the mandible secondary to genioplasty and lefort after two years: a case report and literature review. Iran J Otorhinolaryngol. 2016:28(88):353-6.
10. Hayhurst DL, Moenning JE, Summerlin DJ, Bussard DA. Surgical ciliated cyst: a delayed complication in a case of maxillary orthognathic surgery. J Oral Maxillofac Surg. 1993;51(6):705-8.

11. Koutlas IG, Gillum RB, Harris MW, Brown BA. Surgical (implantation) cyst of the mandible with ciliated respiratory epithelial lining: a case report. Oral Maxillofac Surg. 2002;60(3):324-5.

12. Ragsdale BD, St Jessica LL, Janette AJ, Epker BN. Respiratory implantation cyst of the mandible following orthognathic surgery. J Oral Maxillofac Pathol. 2009;13(1):30-4

13. Li CC, Feinerman DM, MacCarthy KD, Woo SB. Rare mandibular surgical ciliated cysts: report of two new cases. J Oral Maxillofac Surg. 2014;72(9):1736-43.

14. Cai M, Shen G, Lu X, Wang X. Two mandibular surgical ciliated cysts after Le Fort I osteotomy and genioplasty. Br J Oral Maxillofac Surg. 2015;53(10):1040-2

15. Syyed N, Mason R, Thomson E, Downie J. Mandibular respiratory cysts following orthognathic surgery: 2 rare case reports. Int J Surg. 2018;55:S68. https://doi.org/10.1016/j.ijsu.2018.05.316.

16. Takeda Y, Oikawa Y, Furuya I, Satoh M, Yamamoto H. Mucous and ciliated cell metaplasia in epithelial linings of odontogenic inflammatory and developmental cysts. J Oral Sci. 2005;47(2):77-81.

17. Martinelli-Kläy CP, Chatelain S, Salvado F, Lombardi T. Respiratory epithelium lined cyst of the maxilla: differential diagnosis. Case Rep Pathol. 2017. https://doi.org/10.1155/2017/6249649.

18. Drmeddent MI, Schwartz HC. Respiratory implantation cyst of the mandible after chin augmentation: report of case. Otolaryngol Head Neck Surg. 2003;124(5):586-7.

19. Lazar F, zur Hausen A, Mischkowski R, Zöller JE. Atypical cyst formation following chin augmentation using a nasal osteocartilaginous graft. J Cranio-Maxillofac Surg. 2006;34(2):107-12.

20. Anastassov GE, Lee H. Respiratory mucocele formation after augmentation genioplasty with nasal osteocartilaginous graft. J Oral Maxillofac Surg. 1999;57(10):1263-5.

21. Kelly JP, Malik S, Stucki-McCormick SU. Tender swelling of the chin 40 years after genioplasty. J Oral Maxillofac Surg. 2000;58(2):203-6.

22. Imholte $M$, Schwartz HC. Respiratory implantation cyst of the mandible after chin augmentation: report of case. Otolaryngol Head Neck Surg. 2001;124(5):586-7.

23. Flores JR, Gallego MAP, García-Denche JT. Plasma rico en plaquetas: fundamentos biológicos y aplicaciones en cirugía maxilofacial y estética facial. Rev Esp Cirgu Oral Maxilofac. 2012;34(1):8-17.

24. Pavlovic V, Ciric M, Jovanovic V, Stojanovic P. Platelet rich plasma: a short overview of certain bioactive components. Open Med. 2016;11(1):242-7.

25. da Silva Baumgart C, da Silva Lauxen I, Sant'Anna Filho M, de Quadros OF. Epidermal growth factor receptor distribution in pericoronal follicles: relationship with the origin of odontogenic cysts and tumors. Oral Surg Oral Med Oral Pathol Oral Radiol Endodont. 2007;103(2):240-5.

26. Shear M, Speight $P$. Radicular cyst and residual cyst. In: Shear M, Speight $P$ editors. Cysts of the oral and maxillofacial regions. Wiley; 2008. p. 123-43.

27. Kondo M, Tamaoki J, Takeyama K, Isono K, Kawatani K, Izumo T, et al. Elimination of $\mathrm{LL}-13$ reverses established goblet cell metaplasia into ciliated epithelia in airway epithelial cell culture. Allergol Int. 2006;55(3):329-36.

\section{Publisher's Note}

Springer Nature remains neutral with regard to jurisdictional claims in published maps and institutional affiliations. 